\title{
Maximizing the Impact of Control at All Levels
}

\author{
Antonio Visioli * \\ Dipartimento di Ingegneria Meccanica e Industriale, University of Brescia, Brescia, Italy
}

The paper discusses the strategies that should be applied to maximize the impact of control systems in our society. This is achieved, in particular, by revealing the role of control systems (at different levels) in different fields and by reducing the theory/practice gap so that methodologies proposed by academic researchers can be transferred to industry. Some considerations about the role of scientific publications are also made.

Keywords: control systems, theory/practice gap, impact of research, publications, control layers

\section{INTRODUCTION}

Control systems are ubiquitous in our society, and they have played a key role in the advancement of technology. In fact, they have contributed to the development of solutions in many fields that are essential in our life. We can think about, for example, health and medicine, energy, industrial manufacturing processes, transportation, and urban planning. In all these areas, the Institute of Electrical and Electronics Engineers Control Systems Society and the International Federation of Automatic Control have made extensive analysis of what the main research challenges are (Samad and Annaswamy, 2011; Lamnabhi-Lagarrigue et al., 2017), and for sure, it appears that control systems will be the cornerstone of the society of the future, given their capability to provide sustainable progress.

Indeed, it has to be considered that we can find control systems at different layers, from low-level feedback Proportional-Integral-Derivative (PID) controllers, which are directly interfaced with sensors and actuators, to the (supervisory) control of complex systems, which are nowadays very relevant thanks to the development of those paradigms that are dominant, such as the Internet of Things, or Industry 4.0, or cyber-physical systems (Stankovic, 2014; Kumar Khaitan and McCalley, 2015; Vogel-Heuser and Hess, 2016). The interaction of humans with such complex systems is also nowadays extensively considered for the purpose of providing them with strengthened cooperation capabilities.

However, despite the large number of success stories related to the application of control technology, according to a well-known definition coined by Karl Johan Åström, control systems are still a "hidden technology" (Åström, 1999); that is, their role is often not recognized by people whose background is in a different field. This provides evidence that the impact of control systems can still be increased significantly, and disregarding the single application field, this can be considered, in general, as a real challenge for researchers in this field.

\section{THE THEORY-PRACTICE GAP}

One of the possible reasons why it is recognized that the impact of control engineering can be significantly increased is the well-known theory-practice gap, which has been discussed for many years and which seems to be more relevant in the control field than in other engineering fields. This issue has been very well analyzed in a recent article (Samad et al., 2020) by the International Federation of Automatic Control Industry Committee, where important motivations have been 
outlined. From a slightly different perspective, this can be seen as a problem of technology transfer from academic researchers to industry. Without diminishing the importance of basic research, which represents in any case the essential background for any technological advancement, and by always taking into account that scientific and mathematical rigor are necessary at all levels and should never be neglected for any reason, it is worth focusing on the difficulties faced by those who want to perform applied research. For example, in many countries, a research activity is evaluated by taking more into account the scientific impact of the publications (e.g., by considering the number of citations) than its societal/ industrial impact (which is actually more difficult to measure). Then, the pervasiveness of control systems in different fields requires a multidisciplinary approach and the capacity of working in teams where people have different backgrounds and speak different languages. In many cases, the receptiveness of companies (especially small and medium enterprises) to new developments in control systems is scarce because of the lack of knowledge of employees who cannot dedicate much of their work time to the detailed study of a given topic.

It has to be stressed that the theory-practice gap exists in all the previously mentioned control layers: for example, PID controllers for industrial processes are, despite their long history, often found to be badly tuned according to many different surveys (O'Dwyer, 2012). Further, the gap should be reduced by considering methodologies involved in any of the typical phases of the control system design, that is, simply speaking, modeling of the system and analysis of its dynamics; the design of the control algorithm, its validation, and verification (e.g., by advanced simulation tools or hardware-in-the-loop tools); and, finally, its implementation.

Suggestions to the control research community to reduce the gap have been given in Samad et al. (2020) and should be carefully considered. Between them, the role of education deserves to be underlined because it is really important to train people to face the problem. In particular, two issues should be considered. First, control courses should be given in many university programs, so that people who could be exposed to control in their career can perceive its importance (Rossiter et al., 2020). Second, in the courses for those programs mostly related to automation (and also at the $\mathrm{PhD}$ level), the perspective of the application of different methodologies should be always discussed with the students, or in other words, in the explanation of the topics, the students should always be made aware of the problems in applying them in practice.

\section{A THOUGHT ABOUT PUBLICATIONS}

After having given an overview of the problem (of course, from a personal perspective), it is worth focusing on one aspect that is sometimes overlooked in the challenge of reducing the theory-practice gap, that is, those of publications.

There is no question that an article in a journal should contain some novelty and be scientifically rigorous. However, the scientific community should probably think more about the role of dissemination through articles as part of the technology transfer procedure. In this context, presentation of methods that clearly increase the impact of control systems, even if they do not represent a major breakthrough from a theoretical point of view, should be of interest, and the presented methods should be worthy of being published. In addition, authors should clarify as much as possible how the proposed methodologies can be transferred to industry. This implies that the scope of the method should be clearly explained (even if it could appear as quite limited) and its advantages and disadvantages should be clearly outlined, as well as the implementation issues so that a possible user can evaluate as better as possible the cost-benefit ratio in implementing and using such a methodology. For costs, the design effort has to be considered. In fact, there can be cases where small improvements in implementation can provide great benefit for the user from an economic point of view, and these should be made available to the industrial community. For the purpose of simplifying the understanding and implementation of a methodology, it is useful to provide software tools wherever possible.

Finally, the interdisciplinarity of control, which spans across the wide variety of traditional engineering fields, should always be considered. Thus, when proposing a technique for a specific application (which can be at any level in a given engineering area), the explanation should be done by also thinking that people from other fields can take it as an inspiration to find solutions for their specific problems.

\section{CONCLUSIONS}

In addition to providing scientific advancements in control methodologies, academic researchers know the importance of also considering how to remove those barriers that might prevent these methodologies from being applied in practice. Such barriers might be of different types (technological, cultural, or costeffectiveness) and can be present for any control layer (from PID controllers to the control of cyber-physical systems of systems, possibly interacting directly with humans) and for any stage of the control system design: modeling the system, developing the control algorithm, verifying its effectiveness, and implementing it. Each step forward in this direction implies reducing the theory-practice gap and, therefore, improving the technology transfer process. In particular, in publications, the key drivers described in Samad et al. (2020) for the improvement of industrial products/processes should be taken into account as much as possible. In addition to the classical performance indices used in control systems (speed of response, robustness, etc.), cost reduction, energy efficiency, and reliability, just to name a few, are very relevant, and addressing these will help us face the challenge of increasing the impact of control systems in our society.

\section{AUTHOR CONTRIBUTION}

The author confirms being the sole contributor of this work and has approved it for publication. 


\section{REFERENCES}

Åström, K. J. (1999). “Automatic control-the hidden technology,” in Advances in control: highlights of ECC'99. Editors P. M. Frank (London, UK: Springer).

Kumar Khaitan, S., and McCalley, J. D. (2015). Design techniques and applications of cyberphysical systems: a survey. IEEE Syst. J. 9, 350-365. doi:10.1109/JSYST. 2014.2322503

Lamnabhi-Lagarrigue, F., Annaswamy, A., Engell, S., Isaksson, A., Khargonekar, P., Murray, R. M., et al. (2017). Systems \& control for the future of humanity, research agenda: current and future roles, impact and grand challenges. Annu. Rev. Control 43, 1-64. doi:10.1016/j.arcontrol.2017.04.001

O'Dwyer, A. (2012). "An overview of tuning rules for the PI and PID continuoustime control of time-delayed single-input single-output (SISO) processes," in PID control in the third millenium: lessons learned and new approaches. Editors R. Vilanova and A. Visioli (London, UK: Springer).

Rossiter, A., Serbezov, A., Visioli, A., Zakova, K., and Huba, M. (2020). A survey of international views on a first course in systems and control for engineering undergraduates. IFAC J. Syst. Control 13, 100092. doi:10.1016/j.ifacsc. 2020.100092
T. Samad and A. Annaswamy (Editors) (2011). The impact of control technology. New York, NY: IEEE Control Systems Society

Samad, T., Bauer, M., Bortoff, S., Di Cairano, S., Fagiano, L., Fogh Odgaard, P., et al. (2020). Industry engagement with control research: perspective and messages. Annu. Rev. Control 49, 1-14. doi:10.1016/j.arcontrol.2020.03.002

Stankovic, J. A. (2014). Research directions for the internet of things. IEEE Internet of Things J. 1, 3-9. doi:10.1109/JIOT.2014.2312291

Vogel-Heuser, B., and Hess, D. (2016). Guest editorial industry 4.0-prerequisites and visions. IEEE Trans. Autom. Sci. Eng. 13, 411-413. doi:10.1109/TASE.2016. 2523639

Conflict of Interest: The author declares that the research was conducted in the absence of any commercial or financial relationships that could be construed as a potential conflict of interest.

Copyright (C) 2020 Visioli. This is an open-access article distributed under the terms of the Creative Commons Attribution License (CC BY). The use, distribution or reproduction in other forums is permitted, provided the original author(s) and the copyright owner(s) are credited and that the original publication in this journal is cited, in accordance with accepted academic practice. No use, distribution or reproduction is permitted which does not comply with these terms. 